\title{
Antimicrobial resistance and molecular epidemiological typing of Neisseria gonorrhoeae isolates from Kyrgyzstan in Central Asia, 2012 and 2017
}

Saliya Karymbaeva', Iryna Boiko ${ }^{1,2}$, Susanne Jacobsson', Galina Mamaeva ${ }^{3}$, Ainagul Ibraeva ${ }^{3}$, Dilara Usupova ${ }^{3}$, Daniel Golparian ${ }^{1}$ and Magnus Unemo ${ }^{1 *}$

\begin{abstract}
Background: Gonorrhoea and antimicrobial resistance (AMR) in Neisseria gonorrhoeae are significant public health concerns globally. Nearly no gonococcal AMR data are available from Central Asia, and no data from Kyrgyzstan has been published. We examined, for the first time, AMR and molecular epidemiology of $N$. gonorrhoeae isolates cultured in Kyrgyzstan in 2012 and 2017, in order to inform refinements of the Kyrgyz national gonorrhoea management guidelines.

Methods: N. gonorrhoeae isolates cultured in $2012(n=84)$ and $2017(n=72)$ in Kyrgyzstan were examined. MICs of nine antimicrobials were determined using Etest and, where available, clinical breakpoints from the EUCAST were applied. N. gonorrhoeae multiantigen sequence typing (NG-MAST) was also performed.

Results: The overall resistance levels were high to ciprofloxacin (88.5\%), tetracycline (56.9\%), benzylpenicillin (39.1\%), and kanamycin (4.7\%). Resistance to cefixime $(0.6 \%, n=1$ isolate), azithromycin $(0.6 \%, n=1)$, and gentamicin $(0.6 \%$, $\mathrm{n}=1$ ) was rare. No resistance to ceftriaxone or spectinomycin was found. However, the proportion of isolates with decreased susceptibility ( $\mathrm{MIC}=0.125 \mathrm{mg} / \mathrm{L}$ ) to ceftriaxone and cefixime was 12.8 and $11.5 \%$, respectively. Gonococcal isolates were assigned 69 sequence types, of which 52 (75.4\%) were new.
\end{abstract}

\footnotetext{
* Correspondence: magnus_unemo@yahoo.com

'WHO Collaborating Centre for Gonorrhoea and Other STIs, National Reference Laboratory for STIs, Department of Laboratory Medicine, Clinical Microbiology, Faculty of Medicine and Health, Örebro University Hospital, SE-701 85 Örebro, Sweden

Full list of author information is available at the end of the article
}

(c) The Author(s). 2021 Open Access This article is licensed under a Creative Commons Attribution 4.0 International License, which permits use, sharing, adaptation, distribution and reproduction in any medium or format, as long as you give appropriate credit to the original author(s) and the source, provide a link to the Creative Commons licence, and indicate if changes were made. The images or other third party material in this article are included in the article's Creative Commons licence, unless indicated otherwise in a credit line to the material. If material is not included in the article's Creative Commons licence and your intended use is not permitted by statutory regulation or exceeds the permitted use, you will need to obtain permission directly from the copyright holder. To view a copy of this licence, visit http://creativecommons.org/licenses/by/4.0/ The Creative Commons Public Domain Dedication waiver (http://creativecommons.org/publicdomain/zero/1.0/) applies to the data made available in this article, unless otherwise stated in a credit line to the data. 


\begin{abstract}
Conclusions: The gonococcal population in Kyrgyzstan in 2012 and 2017 showed a high genetic diversity. Ceftriaxone, 500-1000 mg, in combination with azithromycin $2 \mathrm{~g}$ or doxycycline, particularly when chlamydial infection has not been excluded, should be recommended as empiric first-line treatment. Spectinomycin $2 \mathrm{~g}$ could be an alternative treatment, and given with azithromycin $2 \mathrm{~g}$ if pharyngeal gonorrhoea has not been excluded. Fluoroquinolones, aminoglycosides, benzylpenicillin, or tetracyclines should not be used for empiric treatment of gonorrhoea in Kyrgyzstan. Timely updating and high compliance to national gonorrhoea treatment guidelines based on quality-assured AMR data is imperative. Expanded and improved gonococcal AMR surveillance in Kyrgyzstan is crucial.
\end{abstract}

Keywords: Neisseria gonorrhoeae, Gonorrhoea, Antimicrobial resistance (AMR), Surveillance, NG-MAST, Ceftriaxone, Cefixime, Azithromycin, Kyrgyzstan

\section{Background}

Gonorrhoea, caused by Neisseria gonorrhoeae, is a significant public health concern globally. In 2016, the World Health Organization (WHO) estimated 87 million new cases of gonorrhoea among adults worldwide, which places gonorrhoea as the second most common bacterial sexually transmitted infection (STI), i.e., after Chlamydia trachomatis infections [1]. N. gonorrhoeae has developed antimicrobial resistance (AMR) to all drugs previously used for the treatment of gonorrhoea. Currently, ceftriaxone is the only remaining effective option for empiric first-line therapy, which is frequently given together with azithromycin in dual therapies [2-16]. However, treatment failures with ceftriaxone, including one with ceftriaxone plus azithromycin dual therapy [13] have been confirmed in many countries [4]. Furthermore, since 2015 an internationally spreading ceftriaxone-resistant strain has been detected in many countries worldwide [16-23] and the first strain with ceftriaxone resistance combined with high-level resistance to azithromycin was detected in both the United Kingdom and Australia in $2018[14,15,24]$. As stressed in the WHO global action plan [25] and the European response plan [26], it is essential to substantially enhance the quality assured surveillance of gonococcal AMR worldwide. Molecular epidemiological typing of gonococci can effectively support the gonococcal AMR surveillance and N. gonorrhoeae multiantigen sequence typing (NG-MAST) has been used in many countries globally [27-33].

Gonococcal infections acquired in, or from, Asia represent most of the confirmed treatment failures with ceftriaxone, and several ceftriaxone-resistant strains appear to have emerged in Asia and subsequently spread globally [4, 34, 35]. In the Kyrgyz Republic (Kyrgyzstan), Central Asia, gonorrhoea is a mandatorily reported infection, which incidence has decreased during the recent decades. The outdated 2005 Kyrgyz national gonorrhoea management guideline recommended treatment with ciprofloxacin $500 \mathrm{mg}$ single oral dose, ceftriaxone 250 $\mathrm{mg}$ intramuscular (IM) dose, cefixime $400 \mathrm{mg}$ single oral dose, or spectinomycin $2 \mathrm{~g}$ IM; and kanamycin $2 \mathrm{~g}$ IM was recommended as an alternative treatment. However, the 2012 Kyrgyz national gonorrhoea management guideline, in which the initial AMR results of the present study were taken into account, recommended dual therapy for gonococcal urethritis: ceftriaxone $250 \mathrm{mg}$ IM or spectinomycin $2 \mathrm{~g}$ IM together with doxycycline $100 \mathrm{mg}$ orally 2 times per day for 7 days or azithromycin $1 \mathrm{~g}$ single oral dose; and cefotaxime $500 \mathrm{mg}$ IM or cefixime $400 \mathrm{mg}$ single oral dose was recommended as alternative treatment [36]. Since 2014, the Ministry of Health of the Kyrgyz Republic is additionally suggesting monotherapy with ceftriaxone $250 \mathrm{mg}$ IM or spectinomycin $2 \mathrm{~g}$ IM for syndromic management; alternative treatment with cefixime $400 \mathrm{mg}$ single oral dose [37]. In Kyrgyzstan, the majority of STI cases are not treated by dermatovenereologists due to reorganisation of the dermatovenerogical services and reforming of the health system, but by primary care physicians, urologists and gynaecologists, mainly private health care providers. In general, very limited gonococcal AMR data is available in the Eastern part of the WHO European Region (i.e. mostly countries earlier belonging to the Soviet Union). Accordingly, limited gonococcal AMR data have only been reported from Russia [33, 38-41], Belarus [42-44], and Ukraine [45, 46]. No AMR or phenotypic/genetic characteristics of $N$. gonorrhoeae strains spreading in Kyrgyzstan have been internationally published.

The aims of the present study were to, for the first time, describe AMR to previous and current treatment options and molecular epidemiology, by means of NGMAST, of $N$. gonorrhoeae isolates cultured in Kyrgyzstan (2012 and 2017). Our quality-assured gonococcal AMR data were used to inform refinements of the 2012 Kyrgyz national gonorrhoea management guideline [36].

\section{Methods}

\section{Gonorrhoea patients and $N$. gonorrhoeae culture}

$N$. gonorrhoeae culture-positive patients with urogenital symptoms (mainly urethral or vaginal discharge) attending the out-patient clinic of the Republican Dermatovenereological Centre, Bishkek, Kyrgyzstan in 2012 and in 
2017 were enrolled in the study. Informed consent was obtained from all included patients and demographic data (sex and age) collected. Exclusion criteria were: i) no verified gonococcal culture and ii) complicated STI. No patient identification information was available in the study. All patients were to be managed in accordance with the Kyrgyz national gonorrhoea management guideline [36], which was updated based on the AMR results of the present study.

$N$. gonorrhoeae isolates were obtained from urethral samples from males and cervical samples from females cultured on selective GCVIT agar plates (3.6\% Difco GC Medium Base agar (BD, Diagnostics, Sparks, MD, USA), supplemented with $1 \%$ IsoVitalex (BD, Diagnostics, Sparks, MD, USA) and 1\% VCNT inhibitor (BD, Diagnostics, Sparks, MD, USA)) incubated in candle jars with extra humidity at $36 \pm 1{ }^{\circ} \mathrm{C}$. All isolates were confirmed as $N$. gonorrhoeae by identification of typical colonies on the selective GCVIT agar plates, Gram-negative diplococci in microscopy, rapid oxidase reaction, and the PhadeBact GC Monoclonal test (Bactus AB, Solna, Sweden), and subsequently preserved as previously described [47]. All examined gonococcal isolates were cultured as part of the routine diagnostics (standard care) [36].

\section{Antimicrobial susceptibility testing}

The minimum inhibitory concentration (MIC; mg/L) of ceftriaxone, cefixime, spectinomycin, azithromycin, ciprofloxacin, benzylpenicillin, tetracycline, gentamicin, and kanamycin were determined using the Etest method (bioMérieux, Marcy-l'Etoile, France), according to the instructions from the manufacturer. All results were interpreted using whole MIC doubling dilutions and, where available, current clinical breakpoints for susceptibility (S) and resistance (R) according to The European Committee on Antimicrobial Susceptibility Testing (EUCAST [48]]. For azithromycin, EUCAST does not recommend any clinical breakpoints, and the EUCAST azithromycin epidemiological cut-off value (ECOFF) of MIC> $1 \mathrm{mg} / \mathrm{L}$ [48] was used to indicate isolates with azithromycin resistance determinants (referred to as resistant hereafter). Previously published interpretative criteria were used for gentamicin [49] and kanamycin $[50,51] . \mathrm{MIC}_{90}$ and $\mathrm{MIC}_{50}$ values were defined as the lowest concentration of the antimicrobial at which $90 \%$ and $50 \%$ of the isolates were inhibited, respectively. $\beta$ lactamase production was identified using a Nitrocefin test (Oxoid, Basingstoke, England). The 2008 WHO $N$. gonorrhoeae reference strains [52] were used for quality controls of all phenotypic and molecular characterisation.

\section{Isolation of genomic DNA}

Bacterial DNA was isolated in the robotised NorDiag Bullet instrument (NorDiag ASA Company, Oslo, Norway) using the BUGS'n BEADS ${ }^{\text {тм }}$ STI-fast kit (NorDiag ASA Company, Oslo, Norway), according to the instructions from the manufacturer.

\section{Molecular epidemiological typing}

Molecular epidemiological typing by means of NGMAST [27] was performed for all viable $N$. gonorrhoeae isolates $(n=143)$, as previously described [52]. NGMAST allele numbers of the more variable segments of por $B$ and $t b p B$, and sequence types (STs) were assigned using the NG-MAST website (www.ng-mast.net).

\section{Statistical analysis}

Statistical analysis was performed using the MedCalc Statistical Software v 19.3.1 (MedCalc Software bvba, Ostend, Belgium). The 95\% confidence interval (95\% CI) was calculated using the exact binominal distribution method. Z-test, Fisher exact and Mann-Whithey U tests, odds ratio (OR) were used for comparison between groups, as appropriate. The level of significance was set at $\mathrm{P}<0.05$.

\section{Results}

Gonorrhoea patients and Neisseria gonorrhoeae isolates In total, $156 N$. gonorrhoeae isolates were cultured from 156 patients (146 males (93.6\%) and 10 females (6.4\%)) attending the out-patient clinic of the Republican Dermatovenereological Centre, Bishkek, Kyrgyzstan, i.e., 84 isolates in 2012 and 72 isolates in 2017. The mean age for the males was 25.7 years (median age: 24 years; range: $18-59$ years; $\mathrm{IQR}=21-27$ ) and for the females 26 years (median age: 26 years; range: $23-32$ years; $\mathrm{IQR}=25-27$ ).

\section{Antimicrobial susceptibility of $N$. gonorrhoeae isolates $(n=156)$ in Kyrgyzstan}

The results of the antimicrobial susceptibility testing of all isolates are summarised in Table 1.

Briefly, the overall proportions of isolates with higher levels of resistance were as follows: ciprofloxacin $88.5 \%$, tetracycline $-56.9 \%$, benzylpenicillin $-39.1 \%$, and kanamycin - $4.7 \%$. Resistance to cefixime, azithromycin, and gentamicin was detected in one isolate each (0.6\%). The susceptibility to all these antimicrobials, except azithromycin, declined from 2012 to 2017. No isolates resistant to ceftriaxone or spectinomycin were identified. The overall proportion of penicillinase-producing $N$. gonorrhoeae (PPNG) isolates was $21.8 \%$, and the proportion of PPNG was stable in 2012 and $2017(P=0.6)$ (Table 1).

Despite that no isolates resistant to ceftriaxone (MIC> $0.125 \mathrm{mg} / \mathrm{L}$ ) were identified, the $\mathrm{MIC}_{90}$ to both 
Table 1 Antimicrobial susceptibility of Neisseria gonorrhoeae isolates ( $n=156)$ from Bishkek, Kyrgyzstan, $2012(n=84)$ and $2017(n=$ 72)

\begin{tabular}{|c|c|c|c|c|c|c|c|c|c|c|}
\hline & & \multicolumn{3}{|l|}{$2012(n=84)$} & \multicolumn{3}{|l|}{$2017(n=72)$} & \multicolumn{3}{|l|}{ Total $(n=156)$} \\
\hline & & 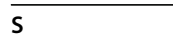 & $\mathrm{I}^{\mathrm{a}}$ & $R^{b}$ & $s$ & $\mathrm{I}^{\mathrm{a}}$ & $R^{b}$ & $s$ & $\mathrm{I}^{\mathrm{a}}$ & $R^{b}$ \\
\hline \multirow[t]{2}{*}{$\overline{C R O}$} & $N$ & 84 & NA & 0 & 72 & NA & 0 & 156 & NA & 0 \\
\hline & $\begin{array}{l}\% \\
(95 \% \mathrm{Cl})\end{array}$ & $\begin{array}{l}100 \\
(95.7-100)\end{array}$ & NA & $\begin{array}{l}0 \\
(0-4.3)\end{array}$ & $\begin{array}{l}100 \\
(95.0-100)\end{array}$ & NA & $\begin{array}{l}0 \\
(0-5.0)\end{array}$ & $\begin{array}{l}100 \\
(97.7-100)\end{array}$ & NA & $\begin{array}{l}0 \\
(0-2.3)\end{array}$ \\
\hline \multirow[t]{2}{*}{ CFM } & $N$ & 84 & NA & 0 & 71 & NA & 1 & 155 & NA & 1 \\
\hline & $\begin{array}{l}\% \\
(95 \% \text { Cl) }\end{array}$ & $\begin{array}{l}100 \\
(95.7-100)\end{array}$ & NA & $\begin{array}{l}0 \\
(0-4.3)\end{array}$ & $\begin{array}{l}98.6 \\
(92.5-100)\end{array}$ & NA & $\begin{array}{l}1.4 \\
(0-7.5)\end{array}$ & $\begin{array}{l}99.4 \\
(96.6-100)\end{array}$ & NA & $\begin{array}{l}0.6 \\
(0.01-3.5)\end{array}$ \\
\hline \multirow[t]{2}{*}{ SPC } & N & 84 & NA & 0 & 72 & NA & 0 & 156 & NA & 0 \\
\hline & $\begin{array}{l}\% \\
(95 \% \mathrm{Cl})\end{array}$ & $\begin{array}{l}100 \\
(95.7-100)\end{array}$ & NA & $\begin{array}{l}0 \\
(0-4.3)\end{array}$ & $\begin{array}{l}100 \\
(95.0-100)\end{array}$ & NA & $\begin{array}{l}0 \\
(0-5.0)\end{array}$ & $\begin{array}{l}100 \\
(97.7-100)\end{array}$ & NA & $\begin{array}{l}0 \\
(0-2.3)\end{array}$ \\
\hline \multirow[t]{2}{*}{ AZM } & $N$ & 83 & NA & 1 & 72 & NA & 0 & 155 & NA & 1 \\
\hline & $\begin{array}{l}\% \\
(95 \% \mathrm{Cl})\end{array}$ & $\begin{array}{l}98.8 \\
(93.5-100)\end{array}$ & NA & $\begin{array}{l}1.2 \\
(0.03-6.5)\end{array}$ & $\begin{array}{l}100 \\
(95-100)\end{array}$ & NA & $\begin{array}{l}0 \\
(0-5.0)\end{array}$ & $\begin{array}{l}99.4 \\
(96.6-100)\end{array}$ & NA & $\begin{array}{l}0.6 \\
(0.01-3.5)\end{array}$ \\
\hline \multirow[t]{2}{*}{$\mathrm{CIP}$} & $N$ & 12 & 0 & 72 & 5 & 1 & 66 & 17 & 1 & 138 \\
\hline & $\begin{array}{l}\% \\
(95 \% \mathrm{Cl})\end{array}$ & $\begin{array}{l}14.3 \\
(7.6-23.6)\end{array}$ & $\begin{array}{l}0 \\
(0-4.3)\end{array}$ & $\begin{array}{l}85.7 \\
(76.4-92.4)\end{array}$ & $\begin{array}{l}6.9 \\
(2.3-15.4)\end{array}$ & $\begin{array}{l}1.4 \\
(0.04-7.5)\end{array}$ & $\begin{array}{l}91.7 \\
(82.8-96.9)\end{array}$ & $\begin{array}{l}10.9 \\
(6.5-16.9)\end{array}$ & $\begin{array}{l}0.6 \\
(0.01-3.5)\end{array}$ & $\begin{array}{l}88.5 \\
(82.4-93.1)\end{array}$ \\
\hline \multirow[t]{2}{*}{ PEN } & $N$ & 6 & 52 & 26 & 3 & 34 & 35 & 9 & 86 & 61 \\
\hline & $\begin{array}{l}\% \\
(95 \% \mathrm{Cl})\end{array}$ & $\begin{array}{l}7.1 \\
(2.6-14.9)\end{array}$ & $\begin{array}{l}61.9 \\
(50.7-72.3)\end{array}$ & $\begin{array}{l}31.0 \\
(21.4-42.0)\end{array}$ & $\begin{array}{l}4.2 \\
(0.9-11.7)\end{array}$ & $\begin{array}{l}47.2 \\
(35.3-59.3)\end{array}$ & $\begin{array}{l}48.6 \\
(36.6-60.7)\end{array}$ & $\begin{array}{l}5.8 \\
(2.7-10.7)\end{array}$ & $\begin{array}{l}55.1 \\
(46.9-63.1)\end{array}$ & $\begin{array}{l}39.1 \\
(31.4-47.2)\end{array}$ \\
\hline \multirow[t]{2}{*}{ TET } & $N$ & ND & ND & ND & 18 & 13 & 41 & \multirow{2}{*}{\multicolumn{3}{|c|}{ Data available only in 2017}} \\
\hline & $\begin{array}{l}\% \\
(95 \% \mathrm{Cl})\end{array}$ & ND & ND & ND & $\begin{array}{l}25 \\
(15.5-36.6)\end{array}$ & $\begin{array}{l}18.1 \\
(10.0-29.0)\end{array}$ & $\begin{array}{l}56.9 \\
(44.7-68.5)\end{array}$ & & & \\
\hline \multirow[t]{2}{*}{ KAN } & N & 47 & 33 & 4 & ND & ND & ND & \multicolumn{3}{|c|}{ Data available only in 2012} \\
\hline & $\begin{array}{l}\% \\
(95 \% \mathrm{Cl})\end{array}$ & $\begin{array}{l}56 \\
(44.7-66.8)\end{array}$ & $\begin{array}{l}39.3 \\
(28.8-50.6)\end{array}$ & $\begin{array}{l}4.7 \\
(1.3-11.7)\end{array}$ & ND & ND & ND & & & \\
\hline \multirow[t]{4}{*}{ GEN } & N & 83 & 1 & 0 & 69 & 2 & 1 & 152 & 3 & 1 \\
\hline & $\begin{array}{l}\% \\
(95 \% \mathrm{Cl})\end{array}$ & $\begin{array}{l}98.8 \\
(93.5-199)\end{array}$ & $\begin{array}{l}1.2 \\
(0.03-6.5)\end{array}$ & $\begin{array}{l}0 \\
(0-4.3)\end{array}$ & $\begin{array}{l}95.8 \\
(88.3-99.1)\end{array}$ & $\begin{array}{l}2.8 \\
(0.4-9.7)\end{array}$ & $\begin{array}{l}1.4 \\
(0.04-7.5)\end{array}$ & $\begin{array}{l}97.4 \\
(93.5-99.3)\end{array}$ & $\begin{array}{l}2 \\
(0.4-5.6)\end{array}$ & $\begin{array}{l}0.6 \\
(0.01-3.5)\end{array}$ \\
\hline & & $n=75$ & & & $n=72$ & & & $n=147$ & & \\
\hline & & \multicolumn{9}{|l|}{ Negative/Positive } \\
\hline \multirow[t]{2}{*}{ PPNG } & N & 60 & \multicolumn{2}{|l|}{15} & 55 & 17 & & 115 & \multicolumn{2}{|l|}{32} \\
\hline & $\%(95 \% \mathrm{Cl})$ & $80(69.2-88.4)$ & \multicolumn{2}{|l|}{$20(11.7-30.8)$} & $76.4(64.9-85.6)$ & \multicolumn{2}{|l|}{$23.6(14.4-35.1)$} & $78.2(70.7-84.6)$ & \multicolumn{2}{|l|}{$21.8(15.4-29.4)$} \\
\hline
\end{tabular}

S, susceptible; I, susceptible, increased exposure; R, resistant; CRO, ceftriaxone; CFM, cefixime; AZM, azithromycin; SPC, spectinomycin; CIP, ciprofloxacin; PEN, benzylpenicillin; TET, tetracycline; KAN, kanamycin; PPNG, penicillinase-producing Neisseria gonorrhoeae; $\mathrm{n}$, number of isolates; Cl, confidence interval; NA, not applicable; ND, Not determined

a microorganism is categorised as "Susceptible, Increased exposure" when there is a high likelihood of therapeutic success because exposure to the agent is increased by adjusting the dosing regimen or by its concentration at the site of infection (www.eucast.org/newsiandr/)

${ }^{b}$ The breakpoints (susceptible/resistant) from the EUCAST [48] were as follows: ceftriaxone and cefixime (MIC $\leq 0.125 />0.125 \mathrm{mg} / \mathrm{L}$ ), azithromycin (MIC $\left.\leq 1 />1 \mathrm{mg} / \mathrm{L}\right)$, spectinomycin (MIC $\leq 64 />64 \mathrm{mg} / \mathrm{L})$, ciprofloxacin (MIC $\leq 0.032 />0.064 \mathrm{mg} / \mathrm{L})$, benzylpenicillin $(\mathrm{MIC} \leq 0.064 />1.0 \mathrm{mg} / \mathrm{L})$, and tetracycline $(\mathrm{MIC} \leq 0.5 />1.0 \mathrm{mg} / \mathrm{L})$.

Previously published breakpoints were used for gentamicin (MIC $\leq 4 />16 \mathrm{mg} / \mathrm{L}[49])$ and kanamycin $(\mathrm{MIC} \leq 4 / \geq 16 \mathrm{mg} / \mathrm{L})[50,51]$

ceftriaxone and cefixime was $0.125 \mathrm{mg} / \mathrm{L}$, which is exactly at the clinical breakpoint for resistance. The overall numbers of isolates with $\mathrm{MIC}=0.125 \mathrm{mg} / \mathrm{L}$ were $12.8 \%(20 / 156)$ and $11.5 \%(18 / 156)$ for ceftriaxone and cefixime, respectively. Nevertheless, the proportion of isolates with extended-spectrum cephalosporin (ESC) MIC $=0.125 \mathrm{mg} / \mathrm{L}$ was not significantly different in 2012 and $2017(P=0.07)$.

\section{Molecular epidemiological characterisation (NG-MAST)} In total, 69 different NG-MAST STs (14 NG-MAST genogroups) were found among the 143 sequenced isolates. Majority of STs $(75.4 \%, 52 / 69)$ had not been previously described. The most common STs were ST1751
$(14.7 \%, n=21)$, ST15952 (4.9\%, $n=7)$, ST368 $(4.2 \%, n=$ 6), ST1691 (4.2\%, n=6), ST569 (3.5\%, $n=5)$, ST807 $(3.5 \%, \mathrm{n}=5)$, and ST15951 $(2.8 \%, n=4)$. Eight different STs $(11.6 \%, 8 / 69)$ represented by three isolates each were found: ST387, ST972, ST10687, ST14617, ST15955, ST15957, ST15961, and ST15981. Ten STs $(14.5 \%, 10 / 69)$ included two isolates each: ST157, ST5941, ST15953, ST15954, ST15958, ST15959, ST15960, ST15968, ST15986, and ST15989. Forty-four STs $(63.8 \%, 44 / 69)$ were represented by a single isolate.

The most common NG-MAST genogroups were G1751 (14.7\%, $n=21)$, G5488 (8.4\%, $n=12)$, G436 (5.6\%, $n=8)$, G386 (4.2\%, $n=6)$, G569 (3.5\%, $n=5)$, G972 $(2.8 \%, n=4)$, and G387 (2.1\%, $n=3)$. Two genogroups 
included two isolates each. Notably, seven isolates $(4.9 \%$, $7 / 143$ ) belonged to several previously described genogroups: G807/G228/G51/G25 (3.5\%, n = 5) and G2862/ G1105 (1.4\%, $n=2)$. Seventy-two isolates $(50.3 \%, 72 /$ 143) were non-groupable. The most common NGMAST genogroups and their MICs of ESCs are summarised in Table 2.

Of all isolates with in vitro decreased susceptibility $(\mathrm{MIC}=0.125 \mathrm{mg} / \mathrm{L})$ to ceftriaxone $(n=17)$ and cefixime $(n=16)$, fourteen $(82.3$ and $87.5 \%$, respectively) were viable at reculture prior to NG-MAST. These isolates belonged to 13 different NG-MAST STs: $15986(n=2)$ and 12 STs comprising single isolate (ST368, ST387, ST569, ST5941, ST2870, ST1318, ST14617, ST15949, ST15960, ST15974, ST15988, and ST15999). Notably, the single isolate resistant to azithromycin (MIC $=6 \mathrm{mg}$ / L) belonged to ST15952 (G5488), while the single isolate resistant to cefixime $(\mathrm{MIC}=0.5 \mathrm{mg} / \mathrm{L})$ was assigned as ST15999 (non-groupable). No isolate belonged to the internationally spreading ST1407 [28, 30, 32].

There was a significant association between ST15952 and resistance to benzylpenicillin ( $\mathrm{OR}=0.11 ; 95 \% \mathrm{CI}$ $0.013-0.92 ; P=0.04)$; ST14617 and PPNG (OR $=0.04$; 95\% CI 0.002-0.8; $P=0.03$ ); and ST15986 and decreased susceptibility to $\mathrm{ESC}$, i.e. $\mathrm{MIC}=0.125 \mathrm{mg} / \mathrm{L} \quad(\mathrm{OR}=0.03$; 95\% CI 0.001-0.6; $\mathrm{P}=0.03$ ). No other association between ST and antimicrobial susceptibility was found, and no STs were specific for sex or age group.

\section{Discussion}

The present study describes the first gonococcal AMR data and molecular characteristics of $N$. gonorrhoeae isolates (obtained in 2012 and 2017) in Kyrgyzstan.

Table 2 Neisseria gonorrhoeae multiantigen sequence typing (NG-MAST) genogroups, sequence types, and minimum inhibitory concentrations (MICs, mg/L) of ceftriaxone and cefixime for Neisseria gonorrhoeae $(n=143)$ isolated in Bishkek, Kyrgyzstan, 2012 and 2017

\begin{tabular}{|c|c|c|c|c|c|c|c|c|c|c|c|}
\hline \multicolumn{2}{|c|}{ NG-MAST (number of isolates) } & \multirow[b]{2}{*}{ ESC } & \multicolumn{9}{|c|}{ Number of isolates with MIC (mg/L): } \\
\hline Genogroups & Sequence types & & $\leq 0.016$ & 0.023 & 0.032 & 0.047 & 0.064 & 0.094 & 0.125 & 0.25 & $\overline{0.5}$ \\
\hline \multirow[t]{2}{*}{$1751(21)$} & $1751(21)$ & CFM & 20 & & 1 & & & & & & \\
\hline & & $\mathrm{CRO}$ & 18 & 1 & 1 & & 1 & & & & \\
\hline \multirow[t]{2}{*}{$5488(12)$} & 15,952 (7), 10,687 (3), 1597 (1), 15,990 (1) & CFM & 10 & 1 & & & & 1 & & & \\
\hline & & $\mathrm{CRO}$ & 11 & & & & & 1 & & & \\
\hline \multirow[t]{2}{*}{$436(8)$} & 1691 (6), 15,964 (1), 15,997 (1) & CFM & 8 & & & & & & & & \\
\hline & & $\mathrm{CRO}$ & 6 & & & 2 & & & & & \\
\hline \multirow[t]{2}{*}{$368(6)$} & $368(6)$ & CFM & 4 & & & 1 & & & 1 & & \\
\hline & & CRO & 5 & & & & & & 1 & & \\
\hline \multirow[t]{2}{*}{$569(5)$} & $569(5)$ & CFM & 2 & 1 & 1 & & & & 1 & & \\
\hline & & $\mathrm{CRO}$ & 3 & & & & & & 2 & & \\
\hline \multirow[t]{2}{*}{$807 / 228 / 51 / 25$ (5) } & $807(5)$ & CFM & 5 & & & & & & & & \\
\hline & & $\mathrm{CRO}$ & 3 & & & & & & 2 & & \\
\hline \multirow[t]{2}{*}{$972(4)$} & $972(3), 2870(1)$ & CFM & 3 & & & & & & 1 & & \\
\hline & & $\mathrm{CRO}$ & 3 & & & & & & 1 & & \\
\hline \multirow[t]{2}{*}{387 (3) } & $387(3)$ & CFM & 2 & & & & & & 1 & & \\
\hline & & CRO & 2 & & & & & & 1 & & \\
\hline \multirow[t]{2}{*}{$340(2)$} & 340 (1), 15,992 (1) & CFM & 1 & 1 & & & & & & & \\
\hline & & $\mathrm{CRO}$ & 1 & 1 & & & & & & & \\
\hline \multirow[t]{2}{*}{$807(2)$} & $5941(2)$ & CFM & 1 & & & & & & 1 & & \\
\hline & & $\mathrm{CRO}$ & 1 & & & & & & 1 & & \\
\hline \multirow[t]{2}{*}{ 2862/1105 (2) } & $2862(1), 15,979(1)$ & CFM & 2 & & & & & & & & \\
\hline & & $\mathrm{CRO}$ & 2 & & & & & & & & \\
\hline \multirow{2}{*}{\multicolumn{2}{|c|}{$\begin{array}{l}\text { Non-grouped (72): } 15951(4), 14,617(3), 15,955(3), 15,957(3), 15,961 \text { (3), 15, } \\
981(3), 157(2), 15,953(2), 15,954(2), 15,958(2), 15,959(2), 15,960(2), 15,968 \\
\text { (2), 15,986 (2), 15,989 (2); } \\
\text { STs presented by single isolate (35) }\end{array}$}} & CFM & 58 & & & & 1 & 3 & 9 & & 1 \\
\hline & & $\mathrm{CRO}$ & 58 & 1 & 1 & 3 & & & 9 & & \\
\hline
\end{tabular}

NG-MAST, Neisseria gonorrhoeae multiantigen sequence typing; MIC, minimum inhibitory concentration; ESC, extended-spectrum cephalosporins; CFM, cefixime; $\mathrm{CRO}$, ceftriaxone 
High prevalence of resistance was observed for previous international first-line antimicrobials such as ciprofloxacin (88.5\%), tetracycline (56.9\%), and benzylpenicillin (39.1\%). Overall, $21.8 \%$ of the gonococcal isolates in Kyrgyzstan were PPNG strains, which cause high-level resistance to benzylpenicillin. Similar high levels of resistance to ciprofloxacin, tetracycline and benzylpenicillin have been described in many other countries in Europe and worldwide [2-7, 25], and none of those antimicrobials can be recommended for empiric first-line therapy of gonorrhoea in Kyrgyzstan as well as in most other countries globally. Our initial AMR results from 2012 formed the basis for refining the national gonorrhoea management guideline in Kyrgyzstan, i.e. to exclude ciprofloxacin and cefixime as recommended empiric first-line treatments and kanamycin as an alternative treatment [36]. Resistance to kanamycin was detected in $4.7 \%$ of isolates, but resistance to cefixime, azithromycin and gentamicin only in one isolate each $(0.6 \%)$. Fortunately, no isolates were resistant to ceftriaxone or spectinomycin. However, 12.8 and $11.5 \%$ of the gonococcal isolates in Kyrgyzstan showed an MIC of $0.125 \mathrm{mg} / \mathrm{L}$ for ceftriaxone and cefixime, respectively. Gonococcal isolates with ESC MICs of $0.125 \mathrm{mg} / \mathrm{L}$ have previously resulted in gonorrhoea treatment failure, particularly in pharyngeal infection, with both cefixime and ceftriaxone $[4,35,53]$. Accordingly, these isolates can be considered to have a decreased in vitro susceptibility to ESCs. Notably, only one Kyrgyz isolate $(0.6 \%)$ was resistant to azithromycin, which is frequently given together with ceftriaxone in the internationally recommended dual treatments of gonorrhoea [7, 9-11]. The increasing resistance to azithromycin internationally is challenging the future inclusion of azithromycin in these dual therapies [3, 4]. Currently, it is also a concern that the resistance to several antimicrobials, including azithromycin, may increase due to the widespread use during the COVID-19 pandemic [54]. Consequently, it is crucial to survey the spread of AMR gonococcal strains and MIC increases, continuously or at a minimum in regular periodic surveys, with special emphasis on ESCs and azithromycin, and ideally also collect improved epidemiological data of patients and monitor failures to cure gonorrhoea with recommended treatment in Kyrgyzstan and globally. In Kyrgyzstan, hopefully this gonococcal AMR surveillance can be expanded outside the capital city Bishkek, i.e. more representative isolates examined from also additional regions of Kyrgyzstan. However, political support, additional funding and training in, for example, appropriate, quality assured sample collection, sample transportation, and gonococcal culture and AMR testing methodologies in additional Kyrgyz laboratories are essential for this expansion.
In general, it is crucial to implement quality-assured gonococcal AMR surveillance in also the neighbouring Central Asian countries as well as other former Soviet Union republics, where the gonococcal AMR surveillance has been exceedingly limited $[55,56]$ and restricted to limited surveillance in Russia, Belarus, and Ukraine [38-46]. Accordingly, among neighbouring Central-Asian countries of Kyrgyzstan, no data have been published from Tajikistan and Uzbekistan, and only very limited molecular typing data from 2008 to 2009 (48 isolates) in Kazakhstan [57]. Notably, the most common NG-MAST ST (ST1751; $n=21)$ in Kyrgyzstan according to our present study was reported from neighbouring Kazakhstan in 2008-2009 [57] and it was also the second most prevalent ST in Russia in 2017 [33]. Furthermore, ST807 represented by five isolates in Kyrgyzstan was the most common gonococcal NGMAST ST in Russia in 2013-2018 [33] and it was also found in one isolate in Kazakhstan in 2008-2009 [57]. These results indicate some larger spread of these gonococcal genotypes in the Central Asian countries and in Russia. Worryingly, reported AMR from neighbouring China has been high, including resistance to ceftriaxone and internationally spreading ceftriaxone-resistant strains have been expanding in China $[21,58,59]$. Accordingly, the possible future import to Kyrgyzstan of ceftriaxone-resistant strains and multidrug-resistant gonococcal strains from China can not be excluded.

Using NG-MAST, the present study showed a diversified population of $N$. gonorrhoeae strains in Kyrgyzstan during 2012 and 2017 with 69 different NG-MAST STs. The high number of unique STs $(n=44,63.8 \%)$ and STs that have not been described earlier $(n=52,75.4 \%)$ may be associated with suboptimal diagnostics (only random gonorrhoea patients and/or isolates are identified), contact tracing (sexual contacts having the identical ST are not traced) and epidemiological surveillance (sexual transmission chains spreading a single ST are not identified or followed-up), STs evolved locally in Kyrgyzstan (STs are not previously described because no NG-MAST studies have previously been performed in the country) or imported from abroad. However, some main ST clusters caused by clonal spread of, e.g., G1751 $(n=21)$, G5488 ( $n=12)$, and G436 $(n=8)$, were identified, which indicate several larger sexual transmission chains. To improve the resolution and accuracy of this molecular typing, it would be of interest to further examine the Kyrgyz strains with whole-genome sequencing (WGS) [60], which have not yet been applied on any gonococcal strains in Central Asia. Using WGS, the Kyrgyz gonococcal population can be compared to the strains spreading in European Union/European Economic Area (EU/EEA) [60, 61], other Eastern European countries such as Ukraine [46], and globally [62-67]. 
The limitations of the present study included that no information about patients' sexual behaviour and their sexual partners, prescribed antimicrobial treatments, and treatment outcomes were available. Furthermore, no extragenital samples were taken (not routine practice in Kyrgyzstan, which may indicate some level of stigmatization regarding gonorrhoea, sexual practices and sexual orientations [6]), and isolates were only collected in the capital city Bishkek (only laboratory with appropriate culture facilities that was found), which represents $15.9 \%$ of the Kyrgyz population. However, the total coverage of investigated $N$. gonorrhoeae isolates to all nationally reported gonorrhoea cases was substantial, i.e. $8.8 \%(84 / 953)$ in 2012 and $15.6 \%(72 / 462)$ in 2017 (https://dgsen.kg), which allows our AMR results to appropriately inform refinements of the national Kyrgyz treatment guideline.

\section{Conclusions}

N. gonorrhoeae isolates cultured in Kyrgyzstan in 2012 and 2017 showed a high genetic diversity and high levels of in vitro resistance particularly to antimicrobials internationally earlier recommended for gonorrhoea treatment. No in vitro resistance to ceftriaxone or spectinomycin was found, but a relatively high level of decreased susceptibility $(\mathrm{MIC}=0.125 \mathrm{mg} / \mathrm{L})$ to ceftriaxone (12.8\%) was documented. Ceftriaxone, 500-1000 $\mathrm{mg}$, in combination with azithromycin $2 \mathrm{~g}$ or doxycycline, particularly when chlamydial infection has not been excluded, should be recommended as empiric first-line treatment. Spectinomycin $2 \mathrm{~g}$ could be an alternative treatment, and given with azithromycin $2 \mathrm{~g}$ if pharyngeal gonorrhoea has not been excluded. Fluoroquinolones, aminoglycosides, benzylpenicillin, or tetracyclines should not be used for empiric treatment of gonorrhoea in Kyrgyzstan. Timely review and updating of and high compliance to national evidence-based gonorrhoea treatment guidelines that are based on quality-assured AMR data is imperative $[3,4,25,68]$. Expanded and improved gonococcal AMR surveillance in Kyrgyzstan is crucial.

\footnotetext{
Abbreviations

AMR: Antimicrobial resistance; AZM: Azithromycin; CFM: Cefixime; Cl: Confidence interval; CIP: Ciprofloxacin; CRO: Ceftriaxone; ECOFF: Epidemiological cut-off; EEA: European Economic Area; ESC: Extended-spectrum cephalosporin; EU: European Union; EUCAST: European Committee on Antimicrobial Susceptibility Testing; G: Genogroup; IM: intramuscular; IQR: Interquartile range; KAN: Kanamycin; MIC: Minimum inhibitory concentration; N: Number; NA: Not applicable; ND: Not determined; NG-MAST: N. gonorrhoeae multiantigen sequence typing; OR: Odds ratio; PEN: Benzylpenicillin; PPNG: Penicillinase-producing Neisseria gonorrhoeae; R: resistance; S: Susceptibility; SPC: Spectinomycin; ST: Sequence type; STI: Sexually transmitted infection; TET: Tetracycline; WGS: Whole genome sequencing; WHO: World Health Organization
}

\section{Acknowledgements}

We are very grateful to all the staff at the Republican Dermatovenerological Centre, Bishkek, Kyrgyzstan.

\section{Authors' contributions}

SK, DU, and MU designed the study. GM, DU, and Al collected the patients and samples. GM, Al, IB, DG, and SJ performed the laboratory work. SK, IB, and $\mathrm{MU}$ wrote the first draft of manuscript. All authors were involved in finalising the manuscript and approved the final version of the manuscript.

\section{Funding}

This work was supported by the Örebro County Council Research Committee and the Foundation for Medical Research at Örebro University Hospital, Örebro, Sweden. Open Access funding provided by Örebro University.

\section{Availability of data and materials}

The data that support the findings of this study are available from the corresponding author upon reasonable request.

\section{Declarations}

\section{Ethics approval and consent to participate}

All examined gonococcal isolates were cultured and preserved as part of the routine diagnostics (standard care), and no patient identification information was available in the study. Informed consent was obtained from all patients. The present study including its protocol was approved by the Expert Committee at the Republican Dermatovenerological Centre, Bishkek, Kyrgyzstan (2011). The whole study including all its methods were carried out in accordance with relevant guidelines and regulations at the Republican Dermatovenerological Centre, Bishkek, Kyrgyzstan, which are all in agreement with the Declaration of Helsinki.

\section{Consent for publication}

Not applicable.

\section{Competing interests}

The authors declare that they have no competing interests.

\section{Author details}

${ }^{1}$ WHO Collaborating Centre for Gonorrhoea and Other STIs, National Reference Laboratory for STIs, Department of Laboratory Medicine, Clinical Microbiology, Faculty of Medicine and Health, Örebro University Hospital, SE-701 85 Örebro, Sweden. ${ }^{2}$ Department of Functional and Laboratory Diagnostics, I. Horbachevsky Ternopil National Medical University, Ternopil, Ukraine. ${ }^{3}$ Republican Dermatovenerological Centre, Bishkek, Kyrgyzstan.

Received: 10 March 2021 Accepted: 1 June 2021

Published online: 12 June 2021

References

1. Rowley J, Vander Hoorn S, Korenromp E, Low N, Unemo M, Abu-Raddad LJ, et al. Chlamydia, gonorrhoea, trichomoniasis and syphilis: global prevalence and incidence estimates, 2016. Bull World Health Organ. 2019;97(8):548-62P. https://doi.org/10.2471/BLT.18.228486.

2. Unemo M, Shafer WM. Antimicrobial resistance in Neisseria gonorrhoeae in the 21st century: past, evolution, and future. Clin Microbiol Rev. 2014;27(3): 587-613. https://doi.org/10.1128/CMR.00010-14.

3. Wi T, Lahra MM, Ndowa F, Bala M, Dillon JR, Ramon-Pardo P, et al. Antimicrobial resistance in Neisseria gonorrhoeae: Global surveillance and a call for international collaborative action. PLoS Med. 2017;14:e1002344.

4. Unemo M, Lahra MM, Cole M, Galarza P, Ndowa F, Martin I, et al. World Health Organization Global Gonococcal Antimicrobial Surveillance Program (WHO GASP): review of new data and evidence to inform international collaborative actions and research efforts. Sex Health. 2019;16(5):412-25. https://doi.org/10.1071/SH19023.

5. Tapsall J. Antimicrobial resistance in Neisseria gonorrhoeae. Geneva: World Health Organization Document Production Services; 2001. https://apps.who. int/iris/bitstream/handle/10665/66963/WHO_CDS_CSR_DRS_2001.3. pdf? sequence $=1 \&$ isAllowed $=y$

6. Unemo M, Seifert HS, Hook EW III, Hawkes S, Ndowa F, Dillon JR. Gonorrhoea. Nat Rev Dis Primers. 2019;5(1):79. https://doi.org/10.1038/s41 572-019-0128-6. 
7. World Health Organization (WHO). WHO guidelines for the treatment of Neisseria gonorrhoeae. Geneva: WHO; 2016 http://www.who.int/ reproductivehealth/publications/rtis/gonorrhoea-treatment-guidelines/en/

8. St Cyr S, Barbee L, Workowski KA, Bachmann LH, Pham C, Schlanger K, et al. Update to CDC's treatment guidelines for gonococcal infection, 2020. MMWR Morb Mortal Wkly Rep. 2020;69(50):1911-6. https://doi.org/10.15585/ mmwr.mm6950a6.

9. Unemo M, Ross J, Serwin AB, Gomberg M, Cusini M, Jensen JS. European guideline for the diagnosis and treatment of gonorrhoea in adults. Int J STD AIDS. 2020;2020:956462420949126. https://doi.org/10.1177/095646242094 9126.

10. Australasian Sexual Health Alliance (ASHA). Gonorrhoea. Australian STI management guidelines for use in primary care: ASHA; 2018. http://www.sti. guidelines.org.au/sexually-transmissible-infections/gonorrhoea\#management

11. Romanowski B, Robinson J, Wong T. Gonococcal infections chapter. Canadian guidelines on sexually transmitted infections. Wong T, LathamCarmanico C, editors. Ottawa, ON: Public Health Agency of Canada; 2013. http://www.phac-aspc.gc.ca/std-mts/sti-its/cgsti-ldcits/assets/pdf/section-56-eng.pdf

12. Fifer H, Saunders J, Soni S, Sadiq ST, FitzGerald M. 2018 UK national guideline for the management of infection with Neisseria gonorrhoeae. Int J STD AIDS. 2020;31(1):4-15. https://doi.org/10.1177/0956462419886775.

13. Fifer $\mathrm{H}$, Natarajan $\mathrm{U}$, Jones $\mathrm{L}$, Alexander S, Hughes $\mathrm{G}$, Golparian D, et al. Failure of dual antimicrobial therapy in treatment of gonorrhea. $N$ Engl J Med. 2016;374(25):2504-6. https://doi.org/10.1056/NEJMc1512757.

14. Eyre DW, Sanderson ND, Lord E, Regisford-Reimmer N, Chau K, Barker L, et al. Gonorrhoea treatment failure caused by a Neisseria gonorrhoeae strain with combined ceftriaxone and high-level azithromycin resistance, England, February 2018. Euro Surveill. 2018;23(27):1800323.

15. Whiley DM, Jennison A, Pearson J, Lahra MM. Genetic characterization of Neisseria gonorrhoeae resistant to both ceftriaxone and azithromycin. Lancet Infect Dis. 2018;18(7):717-8. https://doi.org/10.1016/S1473-3099(18)30340-2.

16. Lahra MM, Martin I, Demczuk W, Jennison AV, Lee Kl, Nakayama SI, et al. Cooperative recognition of internationally disseminated ceftriaxone-resistant Neisseria gonorrhoeae strain. Emerg Infect Dis. 2018;24(4).

17. Terkelsen D, Tolstrup J, Johnsen CH, Lund O, Larsen HK, Worning P, et al. Multidrug-resistant Neisseria gonorrhoeae infection with ceftriaxone resistance and intermediate resistance to azithromycin, Denmark, 2017. Euro Surveill. 2017;22(42):17-00659. https://doi.org/10.2807/1560-7917.ES.201 7.22.42.17-00659.

18. Golparian D, Rose L, Lynam A, Mohamed A, Bercot B, Ohnishi M, et al. Multidrug-resistant Neisseria gonorrhoeae isolate, belonging to the internationally spreading Japanese FC428 clone, with ceftriaxone resistance and intermediate resistance to azithromycin, Ireland, august 2018. Euro Surveill. 2018;23(47):1800617.

19. Nakayama S-I, Shimuta K, Furubayashi K-I, Kawahata T, Unemo M, Ohnishi M. New ceftriaxone and multidrug-resistant Neisseria gonorrhoeae strain with a novel mosaic penA gene isolated in Japan. Antimicrob Agents Chemother. 2016;60(7):4339-41. https://doi.org/10.1128/AAC.00504-16.

20. Lefebvre B, Martin I, Demczuk W, Deshaies L, Michaud S, Labbé AC, et al. Ceftriaxone-resistant Neisseria gonorrhoeae, Canada, 2017. Emerging Infect Dis. 2018;24(2):381-3. https://doi.org/10.3201/eid2402.171756.

21. Chen SC, Yuan LF, Zhu XY, van der Veen S, Yin YP. Sustained transmission of the ceftriaxone-resistant Neisseria gonorrhoeae FC428 clone in China. J Antimicrob Chemother. 2020;75(9):2499-502. https://doi.org/10.1093/jac/dkaa196.

22. Poncin T, Fouere S, Braille A, Camelena F, Agsous M, Bebear C, et al. Multidrug-resistant Neisseria gonorrhoeae failing treatment with ceftriaxone and doxycycline in France, November 2017. Euro Surveill. 2018;23(21).

23. Eyre DW, Town K, Street T, Barker L, Sanderson N, Cole MJ, et al. Detection in the United Kingdom of the Neisseria gonorrhoeae FC428 clone, with ceftriaxone resistance and intermediate resistance to azithromycin, October to December 2018. Euro Surveill. 2019;24(10):1900147. https://doi.org/10.2 807/1560-7917.ES.2019.24.10.1900147.

24. Jennison AV, Whiley D, Lahra MM, Graham RM, Cole MJ, Hughes G, et al. Genetic relatedness of ceftriaxone-resistant and high-level azithromycin resistant Neisseria gonorrhoeae cases, United Kingdom and Australia, February to April 2018. Euro Surveill. 2019;24(8). https://doi.org/10.2807/1 560-7917.ES.2019.24.8.1900118.

25. World Health Organization (WHO). Global action plan to control the spread and impact of antimicrobial resistance in Neisseria gonorrhoeae. Geneva: WHO, 2012. https://apps.who.int/iris/handle/10665/44863
26. European Centre for Disease Prevention and Control. Response plan to control and manage the threat of multi- and extensively drug-resistant gonorrhoea in Europe. Stockholm: ECDC; 2019:1-25.

27. Martin IM, Ison CA, Aanensen DM, Fenton KA, Spratt BG. Rapid sequencebased identification of gonococcal transmission clusters in a large metropolitan area. J Infect Dis. 2004;189(8):1497-505. https://doi.org/10.1 086/383047.

28. Chisholm SA, Unemo M, Quaye N, Johansson E, Cole MJ, Ison CA, et al. Molecular epidemiological typing within the European gonococcal antimicrobial resistance surveillance Programme reveals predominance of a multidrug-resistant clone. Euro Surveill. 2013;18(3):20358.

29. Unemo M, Dillon JA. Review and international recommendation of methods for typing Neisseria gonorrhoeae isolates and their implications for improved knowledge of gonococcal epidemiology, treatment, and biology. Clin Microbiol Rev. 2011;24(3):447-58. https://doi.org/10.1128/ CMR.00040-10.

30. Jeverica S, Golparian D, Matičič M, Potočnik M, Mlakar B, Unemo M. Phenotypic and molecular characterisation of Neisseria gonorrhoeae isolates from Slovenia, 2006-12: rise and fall of the multidrug-resistant NG-MAST genogroup 1407 clone? J Antimicrob Chemother. 2014;69(6):1517-25. https://doi.org/10.1093/jac/dku026.

31. Jabeen K, Bhawan Mal P, Khan E, Chandio S, Jacobsson S, Unemo M. Antimicrobial resistance and Neisseria gonorrhoeae multiantigen sequence typing (NG-MAST) genotypes in N. gonorrhoeae during 2012-2014 in Karachi, Pakistan. BMC Infect Dis. 2016;16(1):353. https://doi.org/10.1186/s12 879-016-1673-1.

32. Mlynarczyk-Bonikowska B, Malejczyk M, Majewski S, Unemo M. Antibiotic resistance and NG-MAST sequence types of Neisseria gonorrhoeae isolates in Poland compared to the world. Postepy Dermatol Alergol. 2018;35:346-51.

33. Shaskolskiy B, Dementieva E, Kandinov I, Chestkov A, Kubanov A, Deryabin $D$, et al. Genetic diversity of Neisseria gonorrhoeae multi-antigen sequence types in Russia and Europe. Int J Infect Dis. 2020;93:1-8. https://doi.org/10.1 016/j.ijid.2020.01.020

34. Tapsall JW, Ndowa F, Lewis DA, Unemo M. Meeting the public health challenge of multidrug- and extensively drug-resistant Neisseria gonorrhoeae. Expert Rev Anti-Infect Ther. 2009;7(7):821-34. https://doi.org/1 0.1586/eri.09.63.

35. Unemo M, Nicholas RA. Emergence of multidrug resistant, extensively drugresistant and untreatable gonorrhea. Future Microbiol. 2012;7(12):1401-22. https://doi.org/10.2217/fmb.12.117.

36. The Ministry of Health of Kyrgyz Republic. [Clinical guidelines for the treatment and diagnosis of syphilis, gonorrhoea, chlamydiosis]. The Order from 17.12.2012 N. 680. http://med.kg/images/MyFiles/KP/derma tovenerologya/7-12_Lechenie_IPPP.pdf. In Russian.

37. The Ministry of Health of Kyrgyz Republic. Syndromic approach to the management of STD patients. Bishkek; 2014. In Russian.

38. Kubanova A, Frigo N, Kubanov A, Sidorenko S, Priputnevich T, Vachnina T, et al. National surveillance of antimicrobial susceptibility in Neisseria gonorrhoeae in 2005-2006 and recommendations of first-line antimicrobial drugs for gonorrhoea treatment in Russia. Sex Transm Infect. 2008;84(4): 285-9. https://doi.org/10.1136/sti.2007.029033.

39. Kubanova A, Frigo N, Kubanov A, Sidorenko S, Lesnaya I, Polevshikova S, et al. The Russian gonococcal antimicrobial susceptibility programme (RUGASP)-national resistance prevalence in 2007 and 2008, and trends during 2005-2008. Euro Surveill. 2010;15(14):19533. https://doi.org/10.2807/ese.1 5.14.19533-en.

40. Kubanova A, Kubanov A, Frigo N, Solomka V, Semina V, Vorobyev D, et al. Russian gonococcal antimicrobial susceptibility programme (RU-GASP) resistance in Neisseria gonorrhoeae during 2009-2012 and NG-MAST genotypes in 2011 and 2012. BMC Infect Dis. 2014;14(1):342. https://doi. org/10.1186/1471-2334-14-342.

41. Kubanov A, Vorobyev D, Chestkov A, Leinsoo A, Shaskolskiy B, Dementieva $E$, et al. Molecular epidemiology of drug-resistant Neisseria gonorrhoeae in Russia (current status, 2015). BMC Infect Dis. 2016;16(1):389. https://doi.org/1 0.1186/s12879-016-1688-7.

42. Glazkova S, Golparian D, Titov L, Pankratova N, Suhabokava N, Shimanskaya I, et al. Antimicrobial susceptibility/resistance and molecular epidemiological characteristics of Neisseria gonorrhoeae in 2009 in Belarus. APMIS. 2011; 119(8):537-42. https://doi.org/10.1111/j.1600-0463.2011.02770.x.

43. Lebedzeu L, Golparian D, Titov L, Pankratava N, Glazkova S, Shimanskaya I, et al. Antimicrobial susceptibility/resistance and NG-MAST characterisation 
of Neisseria gonorrhoeae in Belarus, Eastern Europe, 2010-2013. BMC Infect Dis. 2015;15(1):29. https://doi.org/10.1186/s12879-015-0755-9.

44. Aniskevich A, Shimanskaya I, Boiko I, Golubovskaya T, Golparian D, Stanislavova I, et al. Antimicrobial resistance in Neisseria gonorrhoeae isolates and gonorrhoea treatment in the Republic of Belarus, Eastern Europe, 20092019; August 2020. https://doi.org/10.21203/rs.3.rs-61686/v1.

45. Boiko I, Golparian D, Krynytska I, Bezkorovaina H, Frankenberg A, Onuchyna $\mathrm{M}$, et al. Antimicrobial susceptibility of Neisseria gonorrhoeae isolates and treatment of gonorrhoea patients in Ternopil and Dnipropetrovsk regions of Ukraine, 2013-2018. APMIS. 2019;127(7):503-9. https://doi.org/10.1111/a pm.12948.

46. Boiko I, Golparian D, Jacobsson S, Krynytska I, Frankenberg A, Shevchenko T, et al. Genomic epidemiology and antimicrobial resistance determinants of Neisseria gonorrhoeae isolates from Ukraine, 2013-2018. APMIS. 2020;128(7): 465-75. https://doi.org/10.1111/apm.13060.

47. Unemo M, Olcen P, Berglund T, Albert J, Fredlund H. Molecular epidemiology of Neisseria gonorrhoeae: sequence analysis of the porB gene confirms presence of two circulating strains. J Clin Microbiol. 2002;40(10): 3741-9. https://doi.org/10.1128/JCM.40.10.3741-3749.2002.

48. European Committee on Antimicrobial Susceptibility Testing. Breakpoint tables for interpretation of MICs and zone diameters Version 10.0. https:// www.eucast.org/fileadmin/src/media/PDFs/EUCAST_files/Breakpoint_tables/ v_10.0_Breakpoint_Tables.pdf

49. Brown LB, Krysiak R, Kamanga G, Mapanje C, Kanyamula H, Banda B, et al. Neisseria gonorrhoeae antimicrobial susceptibility in Lilongwe, Malawi, 2007. Sex Transm Dis. 2010;37(3):169-72. https://doi.org/10.1097/OLQ.0b013e3181 bf575c.

50. Castillo MC, Saab OA, Fernandez NP, Nader OM. Holgado AP de Ruiz. Agar dilution method for susceptibility testing of Neisseria gonorrhoeae. Mem Inst Oswaldo Cruz. 1996;91(6):789-93. https://doi.org/10.1590/S0074-02761 996000600028

51. Lesmana M, Lebron Cl, Taslim D, Tjaniadi P, Subekti D, Wasfy MO, et al. In vitro antibiotic susceptibility of Neisseria gonorrhoeae in Jakarta, Indonesia. Antimicrob Agents Chemother. 2001;45(1):359-62. https://doi.org/10.112 8/AAC.45.1.359-362.2001.

52. Unemo M, Fasth O, Fredlund $\mathrm{H}$, Limnios $\mathrm{A}$, Tapsall J. Phenotypic and genetic characterisation of the 2008 WHO Neisseria gonorrhoeae reference strain panel intended for global quality assurance and quality control of gonococcal antimicrobial resistance surveillance for public health purposes. J Antimicrob Chemother. 2009;63(6):1142-51. https://doi.org/10.1093/jac/ dkp098.

53. Allen VG, Mitterni L, Seah C, Rebbapragada A, Martin IE, Lee C, et al. Neisseria gonorrhoeae treatment failure and susceptibility to cefixime in Toronto, Canada. JAMA. 2013;309(2):163-70. https://doi.org/10.1001/jama.2 012.176575 .

54. Kow CS, Hasan SS. Use of azithromycin in COVID-19: a cautionary tale. Clin Drug Investig. 2020;40(10):989-90. https://doi.org/10.1007/s40261-020-00961-z.

55. Unemo M, Ison CA, Cole M, Spiteri G, van de Laar M, Khotenashvili L. Gonorrhoea and gonococcal antimicrobial resistance surveillance networks in the WHO European Region, including the independent countries of the former Soviet Union. Sex Transm Infect. 2013;89(Suppl 4):v42-iv6.

56. Unemo M, Shipitsyna E, Domeika M: Eastern European Sexual and Reproductive Health (EE SRH) Network Antimicrobial Resistance Group. Gonorrhoea surveillance, laboratory diagnosis and antimicrobial susceptibility testing of Neisseria gonorrhoeae in 11 countries of the eastern part of the WHO European region. APMIS. 2011;119:643-649, 9, DOI: https:// doi.org/10.1111/j.1600-0463.2011.02780.x.

57. Kushnir AV, Muminov TA, Bayev Al, Khrapov EA, Filipenko ML. Molecular characterisation of Neisseria gonorrhoeae isolates in Almaty, Kazakhstan, by VNTR analysis, Opa-typing and NG-MAST. Infect Genet Evol. 2012;12(3):5706. https://doi.org/10.1016/j.meegid.2012.01.026.

58. Chen SC, Yin YP, Dai XQ, Unemo M, Chen XS. First nationwide study regarding ceftriaxone resistance and molecular epidemiology of Neisseria gonorrhoeae in China. J Antimicrob Chemother. 2016;71(1):92-9. https://doi. org/10.1093/jac/dkv321.

59. Zheng Z, Liu L, Shen X, Yu J, Chen L, Zhan L, et al. Antimicrobial resistance and molecular characteristics among Neisseria gonorrhoeae clinical isolates in a Chinese tertiary hospital. Infect Drug Resist. 2019;12:3301-9. https://doi. org/10.2147/IDR.S221109.

60. Harris SR, Cole MJ, Spiteri G, Sánchez-Busó L, Golparian D, Jacobsson S, et al. Public health surveillance of multidrug-resistant clones of Neisseria gonorrhoeae in Europe: a genomic survey. Lancet Infect Dis. 2018;18(7):75868. https://doi.org/10.1016/S1473-3099(18)30225-1.

61. Day MJ, Spiteri G, Jacobsson S, Woodford N, Amato-Gauci AJ, Cole MJ, et al. Stably high azithromycin resistance and decreasing ceftriaxone susceptibility in Neisseria gonorrhoeae in 25 European countries, 2016. BMC Infect Dis. 2018;18(1):609. https://doi.org/10.1186/s12879-018-3528-4.

62. Golparian D, Bazzo ML, Golfetto L, Gaspar PC, Schörner MA, Schwartz Benzaken A, et al. Genomic epidemiology of Neisseria gonorrhoeae elucidating the gonococcal antimicrobial resistance and lineages/ sublineages across Brazil, 2015-16. J Antimicrob Chemother. 2020;75(11): 3163-72. https://doi.org/10.1093/jac/dkaa318.

63. Gianecini RA, Golparian D, Zittermann S, Litvik A, Gonzalez S, Oviedo C, et al. Genome-based epidemiology and antimicrobial resistance determinants of Neisseria gonorrhoeae isolates with decreased susceptibility and resistance to extended-spectrum cephalosporins in Argentina in 201116. J Antimicrob Chemother. 2019;74(6):1551-9. https://doi.org/10.1093/jac/ dkz054.

64. Kersh EN, Pham CD, Papp JR, Myers R, Steece R, Kubin G, et al. Expanding U. S. laboratory capacity for Neisseria gonorrhoeae antimicrobial susceptibility testing and whole-genome sequencing through the CDC's Antibiotic Resistance Laboratory Network. J Clin Microbiol. 2020;58:e01461-19.

65. Demczuk W, Martin I, Peterson S, Bharat A, Van Domselaar G, Graham M, et al. Genomic epidemiology and molecular resistance mechanisms of azithromycin-resistant Neisseria gonorrhoeae in Canada from 1997 to 2014. J Clin Microbiol. 2016;54(5):1304-13. https://doi.org/10.1128/JCM.03195-15.

66. Lan PT, Golparian D, Ringlander J, Van Hung L, Van Thuong N, Unemo M. Genomic analysis and antimicrobial resistance of Neisseria gonorrhoeae isolates from Vietnam in 2011 and 2015-16. J Antimicrob Chemother. 2020; 75(6):1432-8. https://doi.org/10.1093/jac/dkaa040.

67. Sánchez-Busó L, Golparian D, Corander J, Grad YH, Ohnishi M, Flemming R, et al. The impact of antimicrobials on gonococcal evolution. Nat Microbiol. 2019;4(11):1941-50. https://doi.org/10.1038/s41564-019-0501-y.

68. Unemo M, Clarke E, Boiko I, Patel C, Patel R. Adherence to the 2012 European Gonorrhoea guideline in the WHO European region according to the 2018-19 international union against sexually transmitted infections European Collaborative Clinical Group Gonorrhoea Survey. Int I STD AIDS. 2020;31(1):69-76. https://doi.org/10.1177/0956462419879278.

\section{Publisher's Note}

Springer Nature remains neutral with regard to jurisdictional claims in published maps and institutional affiliations.

Ready to submit your research? Choose BMC and benefit from:

- fast, convenient online submission

- thorough peer review by experienced researchers in your field

- rapid publication on acceptance

- support for research data, including large and complex data types

- gold Open Access which fosters wider collaboration and increased citations

- maximum visibility for your research: over $100 \mathrm{M}$ website views per year

At $\mathrm{BMC}$, research is always in progress.

Learn more biomedcentral.com/submission 